GRASAS Y ACEITES, 63 (4), OCTUBRE-DICIEMBRE, 355-364, 2012, ISSN: 0017-3495

DOI: $10.3989 /$ gya.047212

\title{
Detection of argan oil adulterated with vegetable oils: New markers
}

\author{
By I. Ourrach ${ }^{a}$, M. Rada $^{\mathrm{b}, *}$, M.C. Pérez-Camino ${ }^{\mathrm{b}}$, M. Benaissa $^{\mathrm{a}}$ and Á. Guinda ${ }^{\mathrm{b}}$ \\ a Université Hassan II, AînChock-BP 5366 Maarif-Casablanca-Morocco

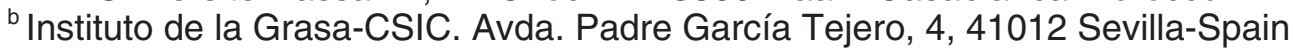 \\ *Corresponding author: mrada@ig.csic.es
}

\section{RESUMEN}

Detección de aceite argán adulterado con aceites vegetales: Nuevos marcadores.

El objetivo principal de este trabajo es contribuir al control de la autenticidad del aceite argán, un producto marroquí muy valorado. Con el fin de detectar la adulteración del aceite de argán con aceites vegetales comestibles, se han estudiado los siguientes parámetros: ácidos grasos, fracción de hidrocarburos, 3,5-estigmastadieno, ésteres alquílicos, pigmentos clorofílicos y propiedades físicas como la viscosidad, densidad e índice de refracción. Los resultados de este estudio muestran que el 3,5-estigmastadieno, kaureno y la feofitina-a podrían utilizarse como nuevos marcadores en la detección del aceite de argán adulterado con aceites refinados y aceite oliva virgen al $5 \%$. La composición en ácidos grasos puede emplearse para la detección de la adulteración del aceite de argán a niveles superiores al $10 \%$, debido a la similitud en la composición de los aceites estudiados. Entre las propiedades físicas analizadas, el índice de refracción mostró diferencias significativas entre el aceite de argán y sus mezclas con el aceite de girasol al $10 \%$.

PALABRAS CLAVE: Aceite de argán - Aceite de girasol - Aceite de oliva - Adulteración - GC - HPLC.

\section{SUMMARY}

Detection of argan oil adulterated with vegetable oils: new markers.

This work aims to contribute to controlling the authenticity of pure argan oil, a valuable Moroccan product. Fatty acids, hydrocarbon fraction, 3,5-stigmastadiene, the alkyl esters of fatty acids, chlorophyllic pigments and physical properties such as viscosity, density and refractive index were studied in order to detect the adulteration of argan oil with edible vegetable oils. The results found in this study show that 3,5-stigmastadiene, kaurene and pheophytin-a can be used as possible new markers for argan oil blends of up to $5 \%$ with refined, sunflower and virgin olive oils. Due to the similarity of the fatty acid compositions of the edible oils studied and argan oil, fatty acids can be employed as markers for the detection of argan oil adulteration at levels higher than $10 \%$. Among the physical properties studied, the refractive index shows significant differences for sunflower oil and its blend at $10 \%$ with argan oil.

KEY-WORDS: Adulteration - Argan oil - GC - HPLC Olive oil - Sunflower oil.

\section{INTRODUCTION}

Argan oil is obtained from the fruits of the argan tree (Argania spinosa) which is an endemic species of south-western Morocco, where it plays a major ecologic and socio-economic role (Khallouki et al., 2003). To protect this unique eco-system, UNESCO declared the Arganeraie a Biosphere Reserve in 1998 (Lybbert et al., 2002). This plant is well adapted to semiarid conditions that exhibit physiological and morphological adjustments in response to drought. However, in a scenario of global change and increase in drought in arid and semi-arid areas, its distribution area is likely to be reduced to milder areas such as the coastal fringe, and it will also be more sensitive to human pressure such as water abstraction and browsing (DíazBarradas et al., 2010).

Argan oil is well known for its bactericidal and fungicidal properties as well as other beneficial effects on health. Moroccan folk medicine uses argan oil based preparations for their hepatoprotective, hypocholesterolemic, and antiatherosclerotic effects, as well as in the treatment of different diseases such as rheumatism, and dermatological or articular pathologies (Moukal 2004; Charrouf and Guillaume 2008). The chemical composition of this oil has been studied and it was shown that the geographical origin of the argan fruit, roasting time and extraction method used to produce the oil have considerable influence on its physico-chemical composition and characteristics (Hilali et al., 2005, Cayuela et al., 2008, Marfil et al., 2008, Harhar et al., 2011; Guinda et al., 2011). A Moroccan norm was created in 2003 to define the quality specifications of virgin argan oil and its classification into different categories; extra virgin argan oil is the highest quality level (Norme Marocaine 2003). Four thousand tons of argan oil are produced in Morocco every year, of which ca. 2500 tons are destined to exportation. The price of argan oil in Europe is approximately 100 euros per liter and is considered a luxury food. Due to its price there is always the possibility that illegal practices will occur such as dilution with cheaper oils (olive oil, colored with paprika or other substances, Gonzálvez et al., 2010). The detection of oil adulteration is a complex problem. Indeed, the 
mixture of two oils of similar composition can be hard to detect as evidenced in olive oil adulteration with hazelnut oil (Christy et al., 2004; Zabaras 2010). At present, studies that discriminate argan oil from other edible oils are scarce. In recent years, Gonzálvez et al., (2010) established the trace element profile of argan oil by means of inductively coupled plasma optical emission measurements in combination with different chemometric approaches. The studies were performed using 16 variables (Na, Mg, Al, K, Ca, Ti, Fe, Co, Ni, Cu, Zn, $\mathrm{Cd}, \mathrm{Pr}, \mathrm{Sm}$, Er and Bi). Hierarchical cluster analysis is able to differentiate sunflower oil samples from the rest, however the discrimination of argan oil from olive, seed and soy oils based on their different trace element compositions is hard to achieve. Rezanka and Rezanková 1999, considered cluster analysis and multidimensional scaling with chisquare measurements of dissimilarity the best methods for the determination of similarity of oils based on percentage contents, fatty acids or triacylglycerols. Analytical detection of possible argan oil adulteration is much easier and shorter when multivariate statistical methods are used. Hilali et al., (2007) proposed campesterol to be an adulteration marker because of its determination level in argan oil, and suggested that it could be the major analysis factor to assess oil purity up to $98 \%$. Campesterol rich oils, (soybean, rapeseed, arachis, sesame) were detected at adulteration levels of $1 \%$. Similar results were obtained with sunflower oil. For the low campesterol containing oils, this method allows for the establishment of a $95 \%$ purity label in the case of olive and hazelnut oil and 98\% purity label for apricot oil. In addition, ferulic acid has been confirmed as a phenolic compound marker to control the authenticity of argan oil (Zougagh et al., 2011). The authors developed a method based on the formation of gold nanoparticles and spectrophotometric analysis to evaluate the adulteration of virgin argan oils.

In order to detect the adulteration of argan oil with edible vegetable oils, the parameters taken into account in this study include 3,5-stigmastadiene, fatty acids alkyl esters, chlorophyllic pigments and hydrocarbons.

Several studies on the characterization of edible vegetable oils by analyzing the hydrocarbon fraction have been reported. Hydrocarbons are the least polar compounds of the unsaponifiable matter of vegetable oils (Moreda et al., 2001). The determination of hydrocarbons by gas chromatography has been used both in the characterization of edible vegetable oils, especially in virgin olive oils; as well as in the fraudulent adulteration of virgin olive oils with cheaper oils. (Lanzón et al., 1989, Webster et al., 2000, Bueno et al., 2005, Guinda et al., 1996). On the other hand, a significant amount of a steroidal compound, 3,5-stigmastadiene, is formed in vegetable oils due to thermal treatment during the refining processes (Lanzón et al., 1994). This compound is derived from the dehydration of $\beta$-sitosterol (Cert et al.,
1994). Depending on the refining conditions, refined vegetable oils showed 3,5-stigmastadiene contents between 1 and $29 \mathrm{mg} \mathrm{kg}^{-1}$ (Dobarganes et al., 1999); therefore, the assessment of stigmastadiene in vegetable oils allows not only for the identification of thermally treated oils but also the detection of virgin olive oil adulteration with refined oils. The alkyl esters of fatty acids are a family of natural neutral lipids present in olive oil and formed by the esterification of free fatty acids with low molecular alcohols. Inappropriate practices during the olive oil extraction process and a low quality olive fruit promote their formation. Blends of extra virgin olive and "soft" refined low quality olive oils can be detected by their alkyl ester concentrations (PérezCamino et al., 2002). The composition of fatty acid alkyl esters in argan oil have not been studied before, however in olive oil, these compounds have been widely studied (Ruiz-Méndez et al., 2003, Pérez-Camino et al., 2008). Therefore, fatty acid alkyl ester analysis was considered interesting to detect the presence of low quality virgin olive oil in argan oil. In this work, chlorophyllic pigments are analyzed in order to detect possible argan oil blends with extra virgin olive oil. This oil presents the combination of green and yellow colors due to the presence of chlorophyll and carotenoid pigments (Gandul-Rojas et al., 2000) which are not present in seed oils. In addition, we considered the study of viscosity in oils interesting for the possible detection of virgin argan oil adulteration, as this physical parameter is directly related to the triacylglycerol composition, the major component of oils. Furthermore, this determination is direct and economical. Finally, we have analyzed other physical properties directly related to the purity of oils such as their density and refractive index.

\section{MATERIALS AND METHODS}

\subsection{Material}

\section{Oils samples}

Sixty percent of the argan oil samples were purchased in a Moroccan market and the rest of the argan oil samples were supplied by the industrial plant Arganoil Company Ltd. The sunflower and olive oils were purchased in a Spanish market. All samples were kept at $-40^{\circ} \mathrm{C}$ until analysis. For identification of the oil blends, see Table 1. Ninetysix oil samples were used to carry out this study.

\section{Reagents and standards}

All reagents were of analytical reagent grade unless otherwise stated. Standards of n-eicosane, 3,5-cholestadiene, methyl heptadecanoate and chlorophyll-a were purchased from Sigma-Aldrich (Sigma-Aldrich Química, Madrid, Spain). The SPE cartridge $(6 \mathrm{~mL})$, packed with silica gel phase $(1 \mathrm{~g})$, was from Varian (EA Middelburg, The Netherlands). 
Table 1

Argan blend oil samples

\begin{tabular}{rcccc}
\hline \multicolumn{5}{c}{ Blend oils } \\
\hline $\mathbf{( \% )}$ & VOO & OO & HOSO & SO \\
\hline 50 & Blend 1 & Blend 2 & Blend 3 & Blend 4 \\
10 & Blend 5 & Blend 6 & Blend 7 & Blend 8 \\
5 & Blend 9 & Blend 10 & Blend 11 & Blend 12 \\
3 & - & Blend 13 & Blend 14 & Blend 15 \\
1 & Blend 16 & Blend 17 & Blend 18 & Blend 19 \\
\hline
\end{tabular}

VOO: Virgin Olive Oil; OO: Olive Oil; HOSO: High Oleic

Sunflower Oil; SO: Sunflower Oil.

\subsection{Fatty acid composition}

The fatty acid composition of the oil samples is determined by gas chromatography as fatty acid methyl esters. The Trans-esterification of triacylglycerides is carried out using a cold methanolic solution of potassium hydroxide, according to the European Union Commission 1991. For the chromatographic determination of fatty acid methyl esters an HP 6890N gas chromatograph (Hewlett-Packard, Palo Alto, CA) equipped with a capillary column (Supelcowax: $60 \mathrm{~m} \times 0.25 \mathrm{~mm} ; 0.25 \mathrm{~mm}$ ), automatic split injector and a flame ionization detector (FID) was used. The carrier gas was hydrogen, with a flow rate of 1 $\mathrm{mL} \mathrm{min}^{-1}$. The temperatures of the injector and detector were held at 210 and $250^{\circ} \mathrm{C}$, respectively. The oven was programmed at $165^{\circ} \mathrm{C}(10 \mathrm{~min})$ and increased by $1,5^{\circ} \mathrm{C} \mathrm{min}^{-1}$ up to $200^{\circ} \mathrm{C}(10 \mathrm{~min})$. The injection volume was $1 \mu \mathrm{L}$. The fatty acid composition is expressed as relative percentage of each fatty acid.

\subsection{Determination of physical properties}

Traditionally, density is determined using a $25 \mathrm{~mL}$ picnometer previously calibrated with distilled water and the dynamic viscosity measurement is determined with a temperature controlled falling ball viscometer or with a rheometer equipped with a coneplate, according to the standards. In this work, a Stabinger SVM 3000 (Anton Paar GmbH Graz, Austria) is employed for the viscosity and density determinations. The filling of the instrument and the cleaning are manual. The SVM is equipped with fast thermostatting (no water bath required) and data measuring, which are carried over to a PC system via the serial interface. A volume of $5 \mathrm{~mL}$ of sample is employed. Each test is carried out three times. For the cell filling, plastic disposable syringes are used and $n$-hexane is employed for the cell cleaning. The resulting values are only accurate to the third and second digit after the comma, for density and viscosity, respectively. Refractive indices were determined with a temperature-controlled Abbe refractometer (Hilger \& Watts Ltd., London, U.K.), using white light for the measurement (IUPAC, 1992,
No. 2102). Each of these three physical parameters was determined at 20 and $40^{\circ} \mathrm{C}$ in all vegetable oils in the study.

\subsection{Hydrocarbon fraction}

\section{Linear hydrocarbon quantification}

The isolation of the hydrocarbon fraction is performed by means of the alkaline hydrolysis of $20 \mathrm{~g}$ of the oil sample spiked with $0.25 \mathrm{~mL}$ of a standard solution of n-eicosane $\left(0.05 \mathrm{mg} \mathrm{mL}^{-1}\right)$, as described by Guinda et al., 1996. The unsaponifiable residue is fractioned by means of a silica gel lowpressure column $(15 \mathrm{~g})$ using hexane as eluent. The fraction collected by eluting with $35 \mathrm{~mL}$ is concentrated to approximately $1 \mathrm{~mL}$. An aliquot of $1 \mu \mathrm{L}$ of this fraction, containing saturated and unsaturated aliphatic hydrocarbons, is analyzed by gas chromatography using an HP 6890N gas chromatograph equipped with a capillary column (SPB5: $10 \mathrm{~m} \times 0.32 \mathrm{~mm}$, Supelco, Bellefonte, PA), split injector and FID detector. The carrier gas is hydrogen with a flow rate of $1 \mathrm{~mL} \mathrm{~min}{ }^{-1}$. The operating conditions were as follows: initial oven temperature of $60^{\circ} \mathrm{C}$ for $1 \mathrm{~min}$ and then programmed at $12^{\circ} \mathrm{C}$ per $\mathrm{min}^{-1}$ up to $280^{\circ} \mathrm{C}$ for $1 \mathrm{~min}$, followed by a $7^{\circ} \mathrm{C} \mathrm{min}{ }^{-1}$ increase up to $340^{\circ} \mathrm{C}$ for $1 \mathrm{~min}$. Injector and detector temperatures were $280^{\circ} \mathrm{C}$ and $350^{\circ} \mathrm{C}$, respectively.

\section{Steroidal hydrocarbons determination}

The quantitative determination of 3,5 stigmastadiene in vegetable oils follows the methodology standardized by IUPAC (Dobarganes et al., 1999). The oil sample $(20 \mathrm{~g})$, spiked with $1 \mathrm{~mL}$ of internal standard (3,5-cholestadiene; $20 \mu \mathrm{g}$ $\mathrm{mL}^{-1}$ ), is saponified and the unsaponifiable is fractioned in a silica gel low-pressure column using hexane as eluent. The first $35 \mathrm{~mL}$ of the eluate were discarded, the following $40 \mathrm{~mL}$ fraction is evaporated until dryness, and the residue is dissolved in $0.5 \mathrm{~mL}$ of heptane. An aliquot of $1 \mu \mathrm{L}$ is analyzed by gas chromatography using an HP 6890 gas chromatograph equipped with a capillary column (SGL5: $30 \mathrm{~m} \times 0.25 \mathrm{~mm} ; 0.25 \mathrm{~mm}$ ), split injector and FID detector. The carrier gas was

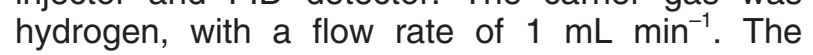
temperatures of the injector and detector were held at 280 and $300^{\circ} \mathrm{C}$ respectively. The oven was programmed at $210^{\circ} \mathrm{C}$ for $5 \mathrm{~min}$ and then increased by $3^{\circ} \mathrm{C} \mathrm{min}^{-1}$ up to $280^{\circ} \mathrm{C}$ (6 min).

\subsection{Alkyl ester quantification}

Methyl and ethyl esters are determined according to the Pérez-Camino et al. (2002) procedure. Briefly, $0.2 \mathrm{~g}$ of the oil sample were dissolved en $1 \mathrm{~mL}$ of hexane and mixed with $500 \mu \mathrm{L}$ of a standard solution of $0.1 \mathrm{mg} \mathrm{mL}^{-1}$ methyl heptadecanoate. A $1 \mathrm{~g}$ silica SPE cartridge fractionated one milliliter of this 
solution. A mixture of hexane/toluene (85:15; v/v) was employed as eluent. The first $7 \mathrm{~mL}$ were discarded and the following $10 \mathrm{~mL}$ fraction was collected and evaporated under reduced pressure. The residue was dissolved in $300 \mu \mathrm{L}$ of heptane. The gas chromatographic determination of the alkyl esters was carried out using an HP 5890 gas chromatograph (Hewlett-Packard, Palo Alto, CA) equipped with a fused silica capillary column coated with cyanopropylsilicone (SPB5 $10 \mathrm{~m} \times 0.32 \mathrm{~mm}$, Supelco, Bellefonte, PA). Hydrogen was used as carrier gas. The initial oven temperature of $70^{\circ} \mathrm{C}$ was increased by $15^{\circ} \mathrm{C} \min ^{-1}$ up to $150^{\circ} \mathrm{C}$; then by $12^{\circ} \mathrm{C}$ min $^{-1}$ up to $340^{\circ} \mathrm{C}$ and maintained for $12 \mathrm{~min}$ at the final temperature. The detector temperature was $350^{\circ} \mathrm{C}$. The injection volume was $1 \mu \mathrm{L}$.

\subsection{Pigment analysis}

Separation of the pheophytins and pyropheophytin pigments was carried out by SPE, according to Hornero-Méndez et al., (2005). After eluting with 12 $\mathrm{mL}$ petroleum ether/diethyl ether solvent mixture 90:10, the major part of the lipids was discarded and a fraction containing the pigments was collected after eluting with $3 \mathrm{~mL}$ acetone. The eluate was analyzed by HPLC (HP 1100; HewlettPackard, Palo Alto, CA) equipped with a stainless steel column $(25 \mathrm{~cm} \times 0.46 \mathrm{~cm}$ i.d.), packed with $5 \mu \mathrm{m}$ C18 Spherisorb ODS-2 (Teknokroma, Barcelona, Spain). An isocratic elution with methanol-acetone-water (36:60:4, v/v/v) was used. Sequential detection was performed with a diode array detector. Pigments were quantified at the wavelength of maximum absorption $(410 \mathrm{~nm})$ with a chlorophyll calibration curve at a concentration range according to the levels of this pigment in virgin olive oil. For the purpose of this determination it was assumed that the response factors of all pigments were equal.

\subsection{Statistical analysis of experimental data}

ANOVA was carried out using the SigmaStat 3.5 statistical pack, (Systat Software Inc.) Each reported value is the mean of two measurements from four replicates. Dunnett's Method of multiple comparisons versus the control group (virgin argan oil) was applied to determine significance among means. Statistical significance was considered at $\mathrm{p}<0.05$.

\section{RESULTS AND DISCUSSION}

The chemical and physical characteristics of pure argan oil, olive and sunflower oils and their blends with argan oil are summarized in Tables 2, 3, 4, 5 and 6. Fatty acid methyl esters, viscosity, density, refractive index, stigmastadiene compound, hydrocarbon fraction, alkyl esters and chlorophyllic pigments, were selected as possible

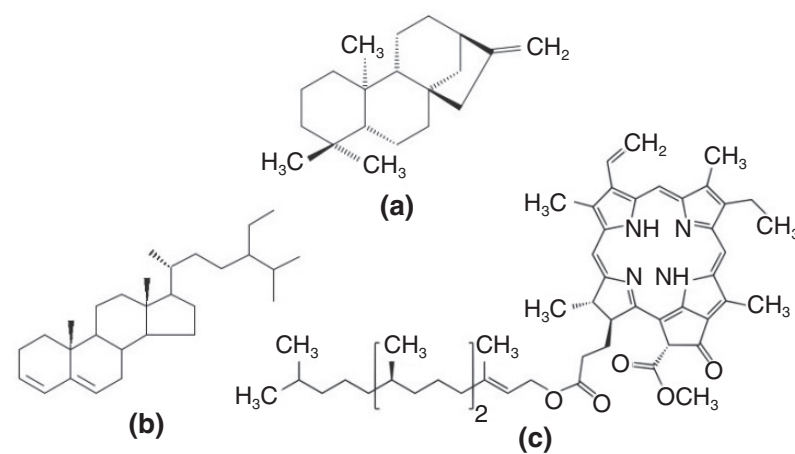

Figure 1

Molecular structures of: kaurene (a), stigmastadiene (b) and pheophytin $a(\mathrm{c})$.

markers for the detection of argan oil contamination or adulteration.

\subsection{Fatty acid methyl esters}

Table 2 shows the results of the analysis of fatty acid methyl esters of argan, other vegetable oils (VOO, OO, HOSO and SO) and their blends with argan oil. The fatty acid compositions of the pure argan oil and the other vegetable oils were in accordance with those found in the literature (Hilali et al., 2005, Cayuela et al, 2008). The major fatty acids in VAO, HOSO and SO were oleic and linoleic acids. The VAO, HOSO and SO oils showed the following relative percentage of oleic and linoleic acids: 45.23 and $35.51 \% ; 79.26$ and $11.15 \% ; 19.68$ and $68.02 \%$, respectively, whereas the major fatty acid present in $\mathrm{VOO}$ and $\mathrm{OO}$, was oleic acid. The VOO and $\mathrm{OO}$ oils showed the following relative percentage of oleic acid: 73.62 and $76.42 \%$, respectively. The results in Table 2 , clearly reveal the fact that the major fatty acids could be used as markers for the detection of argan oil blends with other oils studied when the percentage is higher than $10 \%$ (statistically significant differences, $\alpha=$ $0.05)$. The non-major fatty acid, palmitic acid, with a percentage lower than 12.65 in all the oils studied, only presented significant differences between pure argan oil and its sunflower oils blends at $10 \%$. As shown in Table 2, the minority fatty acids cannot be used to detect any of these argan oil blends. Due to the similarity in fatty acid composition of the edible oils studied and argan oil, the fatty acids cannot be employed as markers for the detection of argan oil adulteration at levels lower than $10 \%$.

\subsection{Physical properties: viscosity, density and refractive index}

Table 3 shows a selection of physical properties of pure argan oil olive and sunflower oils and their blends with argan oil. An average of sixteen samples (VOO and OO) was used for the study of olive oils since value ranges of these parameters are close to each other because this parameter is directly related with triacylglycerol composition. 
Table 2

FAMEs Percentage in pure and blended oils

\begin{tabular}{|c|c|c|c|c|c|c|c|c|c|c|c|c|c|c|c|c|c|c|}
\hline Sample $^{\dagger}$ & C16:0 & SD & C16:1 & SD & C18:0 & SD & C18:1 & SD & C18:2 & SD & C20:0 & SD & C18:3 & SD & C20:1 & SD & C22:0 & SD \\
\hline VAO & 12,65 & 0,25 & 0,10 & 0,01 & 5,73 & 0,29 & 45,23 & 0,77 & 35,51 & 0,89 & 0,35 & 0,02 & 0,26 & 0,03 & 0,35 & 0,02 & 0,11 & 0,01 \\
\hline VOO & $12,04^{*}$ & 0,24 & $0,74^{*}$ & 0,05 & $3,25^{*}$ & 0,20 & $73,62^{*}$ & 1,06 & $8,53^{\star}$ & 0,34 & $0,29^{*}$ & 0,03 & $0,8^{*}$ & 0,05 & $0,28^{*}$ & 0,03 & $0,16^{*}$ & 0,02 \\
\hline 00 & $10,47^{\star}$ & 0,21 & $0,72^{*}$ & 0,05 & $3,75^{*}$ & 0,23 & $76,42^{*}$ & 1,10 & $7,14^{*}$ & 0,29 & $0,40^{*}$ & 0,03 & $0,63^{*}$ & 0,04 & $0,26^{*}$ & 0,03 & $0,14^{*}$ & 0,01 \\
\hline HOSO & $3,68^{*}$ & 0,22 & 0,10 & 0,01 & $4,30^{*}$ & 0,26 & $79,26^{*}$ & 1,14 & $11,15^{\star}$ & 0,22 & $0,21^{*}$ & 0,02 & $0,21^{*}$ & 0,02 & $0,08^{*}$ & 0,01 & $0,7^{*}$ & 0,04 \\
\hline so & $6,62^{*}$ & 0,33 & $0,20^{*}$ & 0,02 & $3,97^{\star}$ & 0,24 & $19,68^{*}$ & 0,49 & $68,02^{*}$ & 0,98 & $0,28^{*}$ & 0,03 & 0,25 & 0,03 & $0,15^{*}$ & 0,02 & $0,69^{*}$ & 0,04 \\
\hline Blend 5 & 12,41 & 0,32 & 0,13 & 0,01 & 5,65 & 0,28 & $49,03^{*}$ & 0,84 & $32,09^{\star}$ & 0,80 & 0,36 & 0,02 & 0,27 & 0,03 & 0,36 & 0,02 & 0,1 & 0,01 \\
\hline Blend 6 & 12,37 & 0,30 & 0,14 & 0,01 & 5,70 & 0,28 & $49,32^{*}$ & 0,84 & $31,82^{*}$ & 0,80 & 0,38 & 0,02 & 0,25 & 0,03 & 0,36 & 0,02 & 0,1 & 0,01 \\
\hline Blend 7 & $11,52^{*}$ & 0,23 & 0,10 & 0,01 & 5,59 & 0,27 & $49,36^{*}$ & 0,85 & $32,64^{*}$ & 0,82 & 0,35 & 0,02 & 0,27 & 0,03 & $0,26^{*}$ & 0,03 & $0,19^{*}$ & 0,02 \\
\hline Blend 8 & $12,07^{\star}$ & 0,24 & 0,09 & 0,01 & 5,72 & 0,29 & $43,53^{*}$ & 0,75 & $37,21^{*}$ & 0,93 & 0,36 & 0,02 & 0,22 & 0,02 & 0,35 & 0,02 & $0,15^{*}$ & 0,02 \\
\hline
\end{tabular}

${ }^{\dagger}$ mean, $\mathrm{n}=8$; * significant difference $(\alpha=0,05)$; C17:0 $\leq 0,1$ in all oils and blended samples. VAO: Virgin Argan Oil; VOO: Virgin Olive Oil; OO: Olive Oil; HOSO: High Oleic Sunflower Oil; SO: Sunflower Oil. See Table 1 for blend descriptions.

The viscosity, density and refractive index of VAO at $20^{\circ} \mathrm{C}$ and $40^{\circ} \mathrm{C}$ were 70.47 and $31.33 \mathrm{mPa} . \mathrm{s}$, 0.9155 and $0.9019 \mathrm{~g} \mathrm{~cm}^{-3}$ and 1.4701 and 1.4631 , respectively. The density and refractive index results are in accordance with the data found in the literature (Belarbi-Benmahdi et al., 2009, Hilali et al., 2005) and Moroccan regulation (Norme Marocaine. 2003).

The data published on the viscosity of argan oil, at $30^{\circ} \mathrm{C}$, by Yaghmur et al., (2001), were consistent with the theoretical extrapolation of our data at the same temperature. In addition, the results on

Table 3

Physical properties of pure and blended oils

\begin{tabular}{|c|c|c|c|c|c|c|}
\hline Sample $^{\dagger}$ & $\eta(\mathrm{mPa} . \mathrm{s})$ & SD & $\square\left(\mathrm{g} \mathrm{cm}^{-3}\right)$ & SD & nt & SD \\
\hline \multicolumn{7}{|c|}{$20^{\circ} \mathrm{C}$} \\
\hline VAO & 70,47 & 1,20 & 0,9155 & 0,0031 & 1,4701 & 0,001 \\
\hline OO/vOO & $80,13^{*}$ & 1,42 & 0,9123 & 0,0030 & $1,4683^{*}$ & 0,001 \\
\hline HOSO & $79,62^{*}$ & 0,83 & 0,9127 & 0,0002 & 1,4695 & 0,001 \\
\hline so & $67,79^{*}$ & 1,01 & 0,9187 & 0,0031 & $1,474^{\star}$ & 0,001 \\
\hline Blend 1/2 & $75,38^{*}$ & 1,50 & 0,9127 & 0,0020 & 1,4693 & 0,001 \\
\hline Blend 3 & $74,70^{*}$ & 1,60 & 0,9134 & 0,0025 & 1,4698 & 0,001 \\
\hline Blend 4 & 68,97 & 1,00 & 0,9162 & 0,0026 & $1,4721^{*}$ & 0,001 \\
\hline Blend 5/6 & 70,60 & 0,98 & 0,9162 & 0,0032 & 1,4699 & 0,001 \\
\hline Blend 7 & 71,68 & 1,40 & 0,9149 & 0,0002 & 1,47 & 0,001 \\
\hline Blend 8 & 70,65 & 1,40 & 0,9151 & 0,0017 & 1,4705 & 0,001 \\
\hline \multicolumn{7}{|c|}{$40^{\circ} \mathrm{C}$} \\
\hline VAO & 31,33 & 0,89 & 0,9019 & 0,0024 & 1,4631 & 0,001 \\
\hline oo/voO ${ }^{\dagger \dagger}$ & $34,81^{*}$ & 0,90 & $0,8987^{*}$ & 0,0012 & $1,4613^{*}$ & 0,001 \\
\hline HOSO & $34,80^{\star}$ & 0,78 & 0,8991 & 0,0020 & 1,4625 & 0,001 \\
\hline so & 30,91 & 0,87 & $0,9060^{\star}$ & 0,0034 & $1,467^{\star}$ & 0,001 \\
\hline Blend 5/6 & 31,79 & 0,95 & 0,8991 & 0,0021 & 1,4623 & 0,001 \\
\hline Blend 7 & 32,00 & 0,88 & 0,8998 & 0,0030 & 1,4628 & 0,001 \\
\hline Blend 8 & 31,34 & 1,03 & 0,9026 & 0,0011 & $1,4651^{*}$ & 0,001 \\
\hline
\end{tabular}

${ }^{\dagger}$ mean, $\mathrm{n}=8 ;{ }^{\dagger \dagger}$ mean, $\mathrm{n}=16$; ${ }^{*}$ significant difference $(\alpha=0,05)$;VAO: Virgin Argan Oil; VOO: Virgin Olive Oil; OO: Olive Oil; HOSO: High Oleic Sunflower Oil; SO: Sunflower Oil. See Table 1 for blend descriptions. 
viscosity, density and refractive index of the oils employed to prepare the blends in this study are in accordance with the literature data. At $20^{\circ} \mathrm{C}$, the viscosity results only present differences between mixtures 50/50 of the olive oils and HOSO with the argan oil (blends $1 / 2$ and 3). None of the studied oils or their mixtures presented significant differences in density values at $20^{\circ} \mathrm{C}$. Nevertheless, at the same temperature, the refractive index shows significant differences only for sunflower oil and its blend at $50 \%$ with argan oil (blend 4), because the values of the refractive index of olive and HOSO oils are close to each other. Although in Table 3 significant differences were observed in the values of the viscosity of pure VAO, HOSO and olive oils, at $40^{\circ} \mathrm{C}$, the argan blends $5 / 6$ and 7 $(10 \%)$ presented no differences $(\alpha=0.05)$. The viscosity determined in these conditions does not serve to detect blends of argan oil with the studied oils up to $10 \%$. The density value of sunflower and olive oils at $40^{\circ} \mathrm{C}$, presented significant differences with argan oil but no significant differences were observed with their mixtures up to $10 \%$ (blends $5 / 6$ and 8). At this temperature, the density does not serve as a parameter to detect blends of argan oil with oils studied up to $10 \%$. The refractive index shows significant differences for sunflower oil and its blend at $10 \%$ with argan oil (blend 8 ) at $40^{\circ} \mathrm{C}$, as well as at $20^{\circ} \mathrm{C}$.

\subsection{Hydrocarbons fraction}

Table 4 shows the results of the hydrocarbon fraction analysis of argan oil, vegetable oils (VOO, $\mathrm{OO}, \mathrm{HOSO}$ and SO) and their VAO blends. The comparison of hydrocarbon fraction composition between the VAO and the other vegetable oils revealed that in sunflower oils, the major hydrocarbons presented are C27, C29 and C31, however in olive oils C29 and C31 are the main hydrocarbons, according to the published data (Bortolomeazzi et al. 2001, Bueno et al. 2005). Figure 2 shows the gas chromatogram of the TLC fraction obtained in the capillary column. Peak 1, was identified as kaurene on the basis of its mass spectra, a diterpene hydrocarbon present in sunflower oils (HOSO and SO) which is absent in olive oils, either virgin or not. Furthermore, the most interesting data observed in Figure 2 is that virgin argan oil does not contain kaurene. Taking into account the results presented in Table 4, kaurene can be considered a possible marker of argan oil adulteration with sunflower oils up to $5 \%$. In accordance with published data, Table 4 presented a kaurene content of 27.18-30.52 ppm and a not identified hydrocarbon content of 52.28-44.81 ppm (RT $12.8 \mathrm{~min}$ ) in sunflower oils HOSO and SO, respectively. One-way analysis of variance of $\mathrm{C} 25$ showed no significant difference $(\alpha=0.05)$ between

Table 4

Hydrocarbon fractions of pure and argan blend oils

\begin{tabular}{|c|c|c|c|c|c|c|}
\hline \multicolumn{7}{|c|}{ Hydrocarbon $\left(\mathrm{mg} \mathrm{kg}^{-1}\right)$} \\
\hline Sample $^{\dagger}$ & $\mathbf{K}$ & $\begin{array}{c}\text { UP } \\
(R T=12.8)\end{array}$ & $\mathrm{C} 25$ & $\mathrm{C} 27$ & C29 & C31 \\
\hline VAO & 0.00 & 0.00 & $0.11 \pm 0.10$ & $1.63 \pm 0.23$ & $2.09 \pm 0.32$ & $2.22 \pm 0.34$ \\
\hline VOO & 0.00 & 0.00 & $6.39 \pm 1.21^{*}$ & $8.98 \pm 1.05^{\star}$ & $10.53 \pm 1.62^{*}$ & $6.98 \pm 0.72^{*}$ \\
\hline $\mathrm{OO}$ & 0.00 & 0.00 & $5.63 \pm 0.92^{*}$ & $10.62 \pm 0.84^{\star}$ & $14.19 \pm 1.15^{\star}$ & $8.21 \pm 1.10^{*}$ \\
\hline HOSO & $27.18 \pm 1.90$ & $52.28 \pm 2.88$ & $8.83 \pm 1.16^{*}$ & $39.21 \pm 2.35^{\star}$ & $54.35 \pm 2.99^{*}$ & $45.02 \pm 2.70^{*}$ \\
\hline SO & $30.52 \pm 2.14$ & $44.81 \pm 2.69$ & $6.78 \pm 0.98^{*}$ & $31.31 \pm 2.19^{*}$ & $76.71 \pm 3.45^{\star}$ & $85.01 \pm 3.83^{*}$ \\
\hline Blend 5 & 0.00 & 0.00 & $0.77 \pm 0.50$ & $1.75 \pm 0.23$ & $2.24 \pm 0.22$ & $1.94 \pm 0.26$ \\
\hline Blend 6 & 0.00 & 0.00 & $0.61 \pm 0.42$ & $2.74 \pm 0.44$ & $2.81 \pm 0.66$ & $1.96 \pm 0.28$ \\
\hline Blend 7 & $1.18 \pm 0.12$ & $3.51 \pm 0.67$ & $0.93 \pm 0.23$ & $5.53 \pm 0.21^{*}$ & $6.32 \pm 1.13^{*}$ & $5.21 \pm 1.08^{*}$ \\
\hline Blend 8 & $1.97 \pm 0.29$ & $2.38 \pm 0.40$ & $0.75 \pm 0.40$ & $2.95 \pm 0.39$ & $6.48 \pm 0.91^{*}$ & $8.08 \pm 1.51^{*}$ \\
\hline Blend 9 & 0.00 & 0.00 & $0.45 \pm 0.24$ & $1.44 \pm 0.22$ & $1.88 \pm 0.29$ & $1.82 \pm 0.28$ \\
\hline Blend 10 & 0.00 & 0.00 & $0.42 \pm 0.22$ & $2.10 \pm 0.32$ & $2.24 \pm 0.35$ & $1.76 \pm 0.27$ \\
\hline Blend 11 & $0.57 \pm 0.29$ & $1.70 \pm 0.26$ & $0.49 \pm 0.26$ & $3.53 \pm 0.55^{\star}$ & $3.95 \pm 0.61$ & $3.40 \pm 0.53$ \\
\hline Blend 12 & $0.96 \pm 0.22$ & $1.17 \pm 0.18$ & $0.39 \pm 0.20$ & $1.95 \pm 0.30$ & $3.78 \pm 0.58$ & $4.77 \pm 0.69^{*}$ \\
\hline Blend 18 & $0.11 \pm 0.10$ & $0.39 \pm 0.21$ & $0.10 \pm 0.10$ & $1.99 \pm 0.31$ & $2.17 \pm 0.34$ & $1.99 \pm 0.31$ \\
\hline Blend 19 & $0.19 \pm 0.10$ & $0.22 \pm 0.14$ & $0.08 \pm 0.10$ & $1.18 \pm 0.18$ & $1.82 \pm 0.28$ & $2.19 \pm 0.34$ \\
\hline
\end{tabular}

${ }^{\dagger}$ mean, $n=8$; ${ }^{2}$ significant difference $(\alpha=0,05)$; VAO: Virgin Argan Oil; VOO: Virgin Olive Oil; OO: Olive Oil; HOSO: High Oleic Sunflower Oil; SO: Sunflower Oil; K: kaurene; UP: unidentified peak. See Table 1 for blend descriptions. 

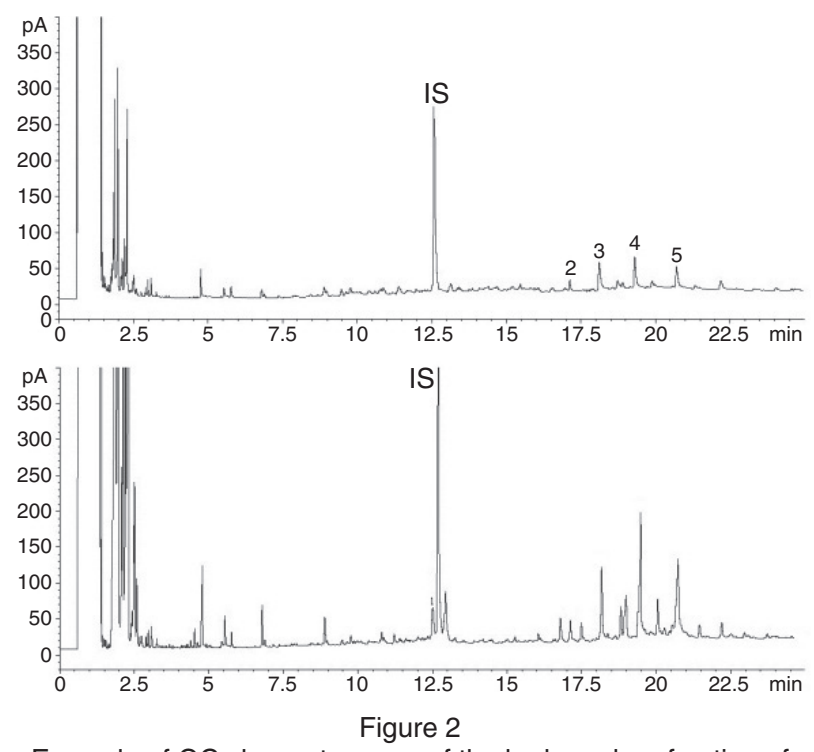

Example of GC chromatograms of the hydrocarbon fraction of VAO (a) and SO blend (b).

the means. In argan oil blends 11 and 7 at 10 and $5 \%$ of $\mathrm{HOSO}, \mathrm{C} 27$ presented significant differences with the pure argan oil. Moreover, in $10 \%$ sunflower oil blends, significant differences were observed in the analysis of C29 and C31, and only the SO blend at $5 \%$ showed differences in $\mathrm{C} 31$.

\subsection{Stigmastadiene compound}

In order to detect the adulteration of virgin argan oil with refined oils (OO, HOSO and $\mathrm{SO}$ ), we studied the stigmastadiene content, a steroid hydrocarbon formed by dehydration of sterols especially from $\beta$-sitosterol. Figure 3 represents the gas chromatograms of virgin argan oil (Fig. 3a) and its blend with $\mathrm{OO}$ (Fig. 3 b). No appreciable content of

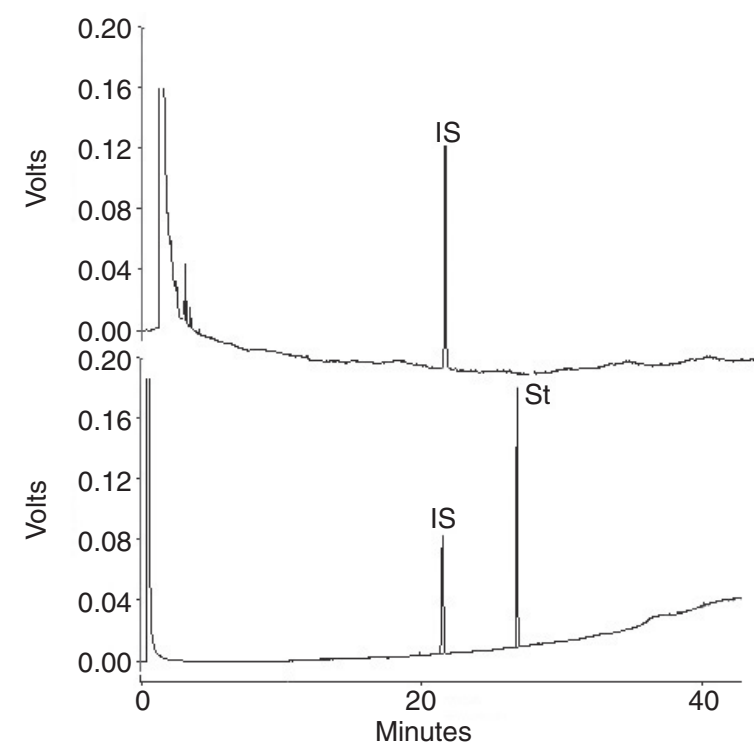

Figure 3

Example of GC chromatograms of the steroidal hydrocarbon fraction of VAO (a) and a refined OO (b). IS. cholesta-3,5-diene and 1. stigmastadiene. stigmastadiene was observed for pure argan oil. Table 5 presents the results of the analysis of stigmastadiene in VAO, refined oils and their blends. The content of stigmastadiene at $5 \% \mathrm{HOSO}$ and SO blends was 0.82 and $0.94 \mathrm{mg} / \mathrm{kg}$ respectively. Furthermore, in the case of olive oil containing 18.35 $\mathrm{mg} \mathrm{kg}^{-1}$ of stigmastadiene, the argan oil blends (5\%) presented a stigmastadiene content of $0.88 \mathrm{mg} / \mathrm{kg}$. All 5\%-refined oil blends presented significant differences in the ANOVA test of stigmastadiene content. From the data reported in Table 5 it can be observed that simply by determining the stigmastadiene content in the studied argan oil blends it can be detected up to $5 \%$ of refined oils. We consider that Mass Spectrometry use in stigmastadiene determination could enable detection of the presence of refined edible oils at lower levels.

\subsection{Alkyl esters of fatty acids}

A bad conservation or over-maturation of olives increases the free fatty acid content and delivery of ethanol and methanol by fermentation. The content of alkyl esters (methyl and ethyl) is regulated for extra virgin olive oil and is limited by law. The aim of fatty acid alkyl ester determination in virgin argan oil was proposed to allow for the detection of mixtures with virgin olive oils of low quality. Figure 4 represents alkyl ester chromatograms of virgin argan oil (a) and a typical olive oil (b). Peaks corresponding to palmitic acid methyl and ethyl esters are present in VAO and OO. In addition, the

Table 5

3,5-stigmastadiene content in VAO and refined oils

\begin{tabular}{lcc}
\hline \multicolumn{1}{c}{ Sample $^{\dagger}$} & $\begin{array}{c}\text { 3,5-stigmastadiene } \\
\left(\mathbf{m g ~ k g}^{-1}\right)\end{array}$ & SD \\
\hline VAO & $\leq 0.1$ & \\
OO & $18.95^{*}$ & 0.76 \\
HOSO & $17.89^{*}$ & 0.90 \\
SO & $20.12^{*}$ & 0.79 \\
Blend 10 & $0.92^{*}$ & 0.03 \\
Blend 13 & $0.63^{*}$ & 0.03 \\
Blend 17 & 0.24 & 0.08 \\
Blend 11 & $0.88^{*}$ & 0.06 \\
Blend 14 & $0.62^{*}$ & 0.06 \\
Blend 18 & 0.24 & 0.08 \\
Blend 12 & $0.94^{*}$ & 0.03 \\
Blend 15 & $0.61^{*}$ & 0.03 \\
Blend 19 & 0.25 & 0.06 \\
\hline
\end{tabular}

${ }^{\dagger}$ mean, $\mathrm{n}=8$; * significant difference $(\alpha=0,05)$; VAO: Virgin Argan Oil; VOO: Virgin Olive Oil; OO: Olive Oil; HOSO: High Oleic Sunflower Oil; SO: Sunflower Oil. See Table 1 for blend descriptions. 


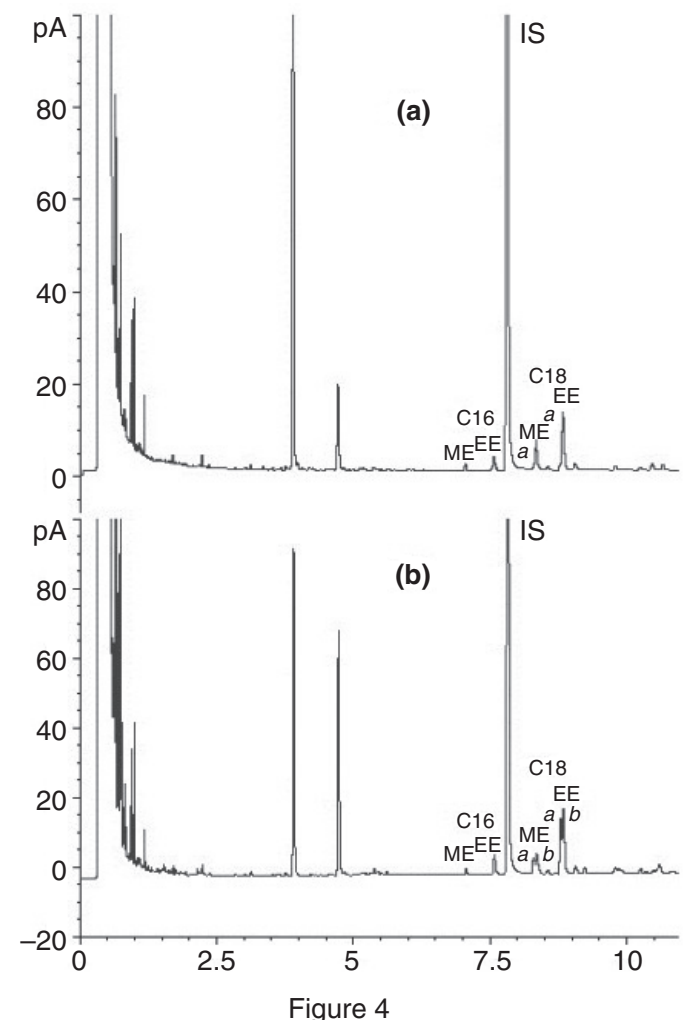

Alkyl ester chromatograms of VAO (a) and OO (b). Peaks correspond toC16:0 and C18 methyl and ethyl esters. $a=\mathrm{C} 18: 1, b=\mathrm{C} 18: 2$ monounsaturated methyl and ethyl esters (oleic acid) are present in both oils (Figs. $4 a$ and b), while linoleic acid methyl and ethyl esters are present only in virgin argan oil (Fig. 4b). The alkyl esters of the fatty acid profiles of both argan oil and olive oil are similar so this method is not able to detect argan oil adulteration with olive oil. We suppose that the presence of these compounds in the virgin argan oil could be due to inappropriate storage conditions of argan seeds. It would be interesting to study these compounds as possible quality parameter of virgin argan oil.

\subsection{Chlorophyllic pigments}

The color of virgin olive oil is the result of the combination of green and yellow colors due to the presence of chlorophyll and carotenoid pigments. In addition, chlorophyll is transformed by the action of temperature and acidic environment in feofitine (pheo- $a, a^{\prime}, b$ and $b^{\prime}$ ) which is quickly degraded by the action of different treatments in pirofeofitine (Gandul-Rojas et al., 2000). In order to detect possible argan oil blends with VOO, chlorophyllic pigments were determined. Figure 5 shows typical HPLC chromatograms of pigment extracts of the following oils: virgin argan, virgin olive and blend 1 . Pheo-a was the main chlorophyll derivative present in virgin olive oil. The chlorophyllic pigments obtained by chromatographic separation of the pigment extracts of the studied oils are listed in Table 6 . The occurrence of chlorophyll derivatives
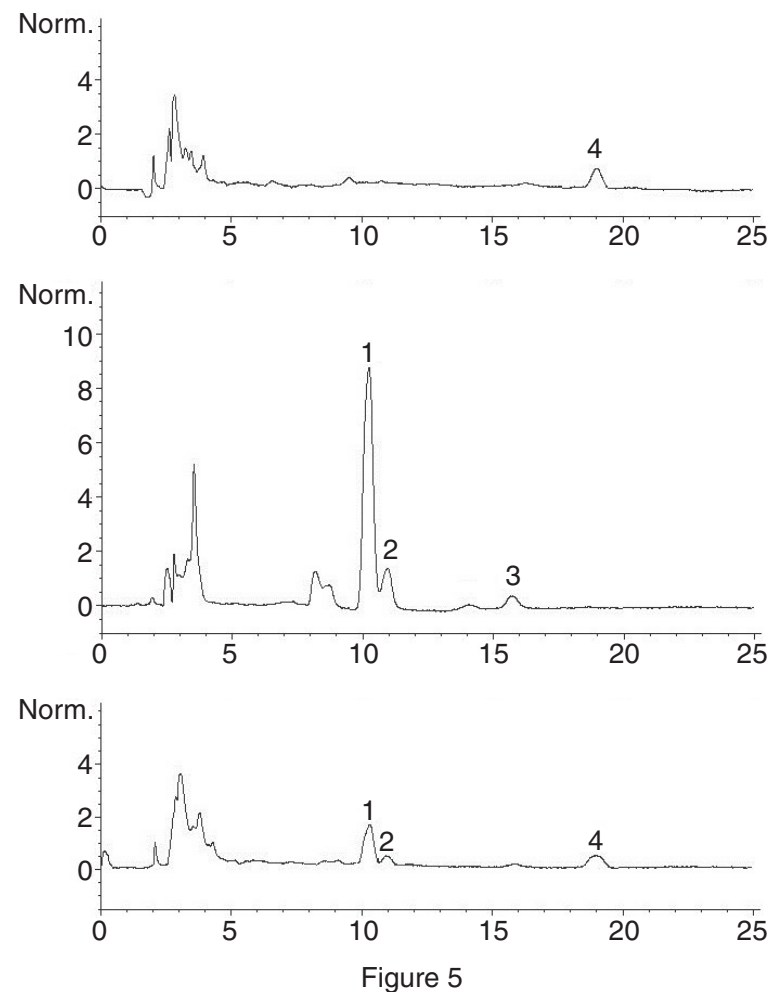

HPLC chromatogram (410 nm) of the chlorophyllic pigment extracts: VAO (a) VOO (b) and blend 1 (c). 1. pheophytin $a$;

2. pheophytin $a^{\prime} ; 3$. pyropheophytin $a$ and 4 . unidentified peak $(R T=18,97 \mathrm{~min}$ ).

in $\mathrm{VOO}$ is in agreement with the previous findings. These compounds are absent in the virgin argan oil, due to their absence in its raw material, as well as other seed oils. The pheo-a analysis (Table 6) showed a $0.68 \mathrm{mg} / \mathrm{kg}$ content in virgin argan oil blends at 5\% VOO. Therefore, pheophytin-a could be a possible marker of virgin olive oil contamination in virgin argan oil with up to $5 \%$.

In agreement with the results found in this study it can be concluded that stigmastadiene, kaurene hydrocarbon and pheophytin-a can be used as possible markers for argan oil blends of up to $5 \%$. Our findings show for the first time that stigmastadiene can be a potential marker to detect refined edible oil adulteration in virgin argan oil at a level of $3 \%$, and an alternative to sunflower oil detection is the determination of the kaurene hydrocarbon. To detect virgin olive oils, pheophytin-a can be a possible marker. More highly sensitive analytical techniques are suggested for lower level adulterations of virgin argan oil (GC-MS, LC-MS).

The findings presented here may contribute to controlling the authenticity of pure argan oil, a valuable Moroccan product.

\section{ACKNOWLEDGEMENTS}

The authors are grateful to the Spanish Agency for the International Cooperation (AECID-MAE) for financing the Project $A 1 / 038569 / 11$. 
Table 6

Chlorophyllic pigment contents in virgin oils and blends

\begin{tabular}{|c|c|c|c|c|}
\hline Sample $^{\dagger}$ & $\begin{array}{l}\text { pheophytin } a \\
\left(\mathrm{mg} \mathrm{kg}^{-1}\right)\end{array}$ & $\begin{array}{l}\text { pheophytin } a^{\prime} \\
\left(\mathrm{mg} \mathrm{kg}^{-1}\right)\end{array}$ & $\begin{array}{l}\text { pyropheophytin a } \\
\left(\mathrm{mg} \mathrm{kg}^{-1}\right)\end{array}$ & $R T=18,97^{t \dagger}$ \\
\hline VAO & nd & nd & nd & $0,40^{b}$ \\
\hline VOO & $12.55^{\mathrm{a}}$ & $2.58^{a}$ & $0.80^{b}$ & nd \\
\hline blend 9 & $0.68^{b}$ & $0.14^{b}$ & $0.05^{b}$ & $0.36^{b}$ \\
\hline blend 16 & $0.14^{b}$ & $0.04^{b}$ & nd & $0.39^{b}$ \\
\hline
\end{tabular}

${ }^{\dagger}$ mean, $\mathrm{n}=8$; ${ }^{\dagger \dagger}$ unidentified peak; $\mathrm{nd}=$ not detected; $\mathrm{aCV}=5 \%$; bCV = 10\%.);VAO: Virgin Argan Oil;

VOO: Virgin Olive Oil. See Table 1 for blend descriptions.

\section{REFERENCES}

Belarbi-Benmahdi M, Khaldi D, Beghdad C, Gouzi H, Bendimerad N. 2009. Physicochemical and nutritional study of argan oil (Argania spinosa L.) in southwestern Algeria. Pigment Resin Technol. 38 (2), 9699.

Bortolomeazzi R, Berno P, Pizzale L, Conte LS. 2001. Sesquiterpene, alkene, and alkane hydrocarbons in virgin olive oils of different varieties and geographical origins. J. Agric. Food Chem. 49, 3278-3283.

Bueno EO, Casas JS, García AM, González LG. 2005. Discriminating power of the hydrocarbon content from virgin olive oil of extremadura cultivars. J. Am. Oil Che. Soc. 82, 1-6.

Cayuela JA, Rada M, Pérez-Camino MC, Benaissa M, Elamrani A, Guinda Á. 2008. Characterization of artisanally and semiautomatically extracted argan oils from Morocco. Eur. J. Lipid Sci. Technol. 110, 11591166.

Cert A, Lanzón A, Carelli AA, Albi T. 1994. Formation of 3,5-stigmastadiene in vegetable oils. Food Chem. 49, 287-293.

Charrouf Z and Guillaume D. 2008. Review. Argan oil: Occurrence, composition and impact on human health. Eur. J. Lipid Sci. Technol. 110, 632-636.

Christy AA, Kasemsumran S, Du Y, Ozak Y. 2004. The detection and quantification of adulteration in olive oil by near infrared spectroscopy and chemonetrics. Anal. Sci. 20, 935-940.

Díaz-Barradas MC, Zunzunegui M, Ain-Lhout F, Jáuregui $\mathrm{J}$, Boutaleb S, Álvarez-Cansimo L, Esquivias M. 2010. Seasonal physicological responses of argania spinosa tree from mediterranean to semi-arid. Climate Plant Soil. 337, 217-231.

Dobarganes MC, Cert A, Dieffenbacher A. 1999. The determination of stigmastadienes in vegetable oils. Pure Appl. Chem. 71, 349-359.

European Union Commission 1991. COMMISSION REGULATION (EEC) № 2568/91 ANNEX X B. Preparation of the fatty acid methyl esters from olive oil and olive-pomace oil.

Gallardo-Guerrero L, Gandul-Rojas B, Roca M, MínguezMosquera MI. 2005. Effects of storage on the original pigment profile of Spanish olive oils. J. Am. Oil. Chem. Soc. 82, 33-39.

Gandul-Rojas B, Cepero MR, Mínguez-Mosquera MI. 2000. Use of chlorophyll and carotenoid pigment composition to determine authenticity of virgin olive oil. J. Am. Oil Chem. Soc. 77, 853-858.

Gonzálvez A, Armenta S, Guardia MDeLa. 2010. Adulteration detection of argan oil by inductively coupled plasma optical emission spectrometry. Food Chem. 121, 878-886.
Guinda A, Lanzón A, Albi T. 1996. Differences in hydrocarbons of virgin olive oils obtained from several olive varieties. J. Agric. Food Chem. 44, 1723-1726.

Guinda A, Rada M, Delgado T, Castellano JM. 2011. Pentacyclic triterpenic acids from arganda spinosa. Eur. J. Lipid Sci. Technol. 113, 231-237.

Harhar H, Gharby S, Kartah B, Elmonfalouti H, Guillaume D, Charrouf Z. 2011. Influence of argan kernel roasting time on virgin argan oil composition and oxidative stability. Plant Foods Hum. Nutr. 66, 163168.

Hilali H, Charrouf Z, Soulhi A, Hachimi L, Guillaume D. 2007. Detection of argan oil adulteration using quantitative campesterol GC-analysis. J. Am. Oil Chem. Soc. 84, 761-764.

Hilali M, Charrouf Z, El Aziz Soulhi A, Hachimi L, Guillaume D. 2005. Influence of origin and extraction method on argan oil physico-chemical characteristics and composition. J. Agric. Food Chem. 53, 20812087.

Hornero-Méndez D, Gandul-Rojas B, Minguez-Mosquera MI. 2005. Routine and sensitive SPE-HPLC method for quantitative determination of pheophytin a and pyropheophytin a in olive oils. Food Res International 38, 1067-1072.

Khallouki F, Younos C, Soulimani R, Oster T, Charrouf Z, Spieglehalder B, Batsch H, Owen RW. 2003. Consumption of argan oil (Morocco) with its unique profile of fatty acids, squalene, sterols, tocopherols and phenolic antioxidants should confer valuable cancer chemopreventive effects. Eur. J. Cancer Prev. 12, 67-75.

Lanzón A, Albi T, Cert A, Gracián J. 1994. The hydrocarbon fraction of virgin olive oil and changes resulting from refining. J. Am. Oil Chem. Soc. 71, 285-291.

Lanzón A, Cert A, Albi T. 1989. Detección de la presencia de aceite de oliva refinado en el aceite de oliva virgen. Grasas Aceites. 40, 385-388.

Lybbert TJ, Barrett CB, Narjisse H. 2002. Market-based conservation and local benefits: the case of argan oil in Morocco. Ecological Economics 41,125-144.

Marfil R, Cabrera-Vique C, Giménez R, Bouzas PR, Martínez O, Sánchez JA. 2008. Metal content and physicochemical parameters used as quality criteria in virgin argan oil: Influence of the extraction method. J. Agric.. Food Chem 56, 7279-7284.

Moreda W, Perez-Camino MC, Cert A. 2001. Gas and liquid chromatography of hydrocarbons in edible vegetable oils. J. Chromatogr. A 936, 159-171.

Moukal A. 2004. L'arganier, argania spinosa L. (Skeels), usage therapeutique, cosmetique et alimentaire. Phytoterapie 2, 135-141. 
Norme Marocaine. PNM 08.5.090. 2003. Corps gras d'origines animale et végétale. Huiles d'argane spécifications. Ministry of Industry, Trade, Energy and Mines. Rabat, 2003.

Perez-Camino MC, Cert A, Romero-Segura A, CertTrujillo R, Moreda W. 2008. Alkyl esters of fatty acids a useful tool to detect soft deodorized olive oils. J. Agric. Food Chem. 56, 6740-6744.

Perez-Camino MC, Moreda W, Mateos R, Cert A. 2002. Determination of esters of fatty acids with low molecular weight alcohols in olive oils. J. Agric. Food Chem 50, 4721-4725.

Rezanka T, Rezanková H. 1999. Characterization of fatty acids and triacylglycerols in vegetable oils by gas chromatography and statistical analysis. Analytica Chimica Acta. 398, 253-261.
Ruiz-Méndez MV, Ramos-Hinojosa ÁE. 2003. Fatty acid esters with short-chain alcohols in two-phase olive pomace oils. Eur J Lipid Sci Technol 105, 346-350.

Webster L, Simpson P, Shanks AM, Moffat CF. 2000. The authentication of olive oil on the basis of hydrocarbon concentration and composition. The Analyst 125, 97-104.

Yaghmur A, Aserin A, Mizrahi Y, Nerd A, Garti N. 2001. Evaluation of argan oil for deep-fat frying. Lebensm. Wiss. Technol .34, 124-130.

Zabaras D. 2010. Olive oil adulteration with hazelnut oil and analytical approaches for its detection, en Victor R. Preedy and Ronald Ross (Eds.) Olives and Olive Oil in Health and Disease Prevention. Elsevier Inc., págs. 441-450.

Zougagh M, Salghi R, Dhair S, Rios A. 2011. Nanoparticle-based assay for the detection of virgin argan oil adulteration and its rapid quality evaluation. Anal. Bioanal Chem. 399, 2395-2405. 